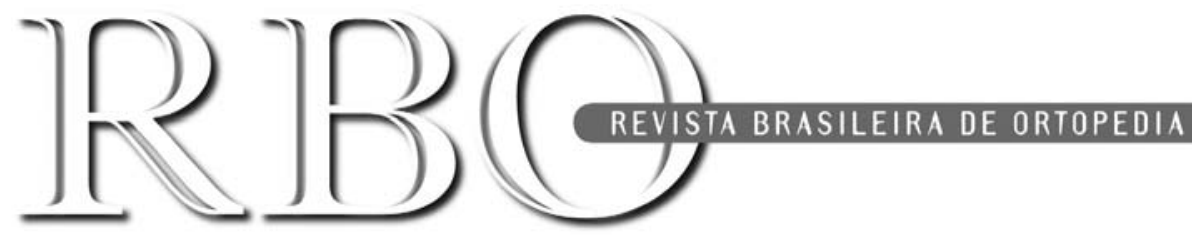

\title{
Editorial
}

\section{O PRIMEIRO VOLUME DA RBO EM 1939 E A OBSTINAÇÃO DE ACHILLES DE ARAÚJO}

\author{
Osvandré Lech
}

O nome por trás do primeiro volume da $R B O$ se chama ACHILLES DE ARAÚJO. Este carioca, mítico fundador e segundo presidente da SBOT em 1937-38, entendeu a necessidade de estabelecer bases científicas para a novel sociedade ortopédica. Com a colaboração de alguns autores ele conseguiu editar o primeiro volume já em 1939.

No parágrafo final da Apresentação, Achilles de Araújo define as bases filosóficas da nova publicação, que nos inspira até os dias de hoje: "A Revista Brasileira de Orthopedia e Traumatologia apparece como uma consequencia lógica dessas affirmativas e está certa que, reunindo e divulgando a producção technicoscientifica dos cultores da especialidade no Brasil e, tornando-se como deseja, campo efficiente de estudo dos múltiplos e complexos problemas medico-sociaes que a Orthopedia e Traumatologia ainda apresentam, está certa, repetimos, que fará obra útil e patriótica".

Abaixo, a carta que ele explica ao seu colega Renato da Costa Bonfim o intenso momento profissional que vivia.

Rio, 15.7.1939

Meu caro Renato

Um forte abraço

Escrevo-lhe apressadamente para aproveitar a boa vontade do Zezito Marcondes de Souza em levar estas linhas. Estou "abafadíssimo" de serviço: Congresso de Cirurgia, Clínica e sobretudo Revista Brasileira de Ortopedia e Traumatologia, sem falar na S.B.O.T.

Com relação a esta última, ainda não há nada de positivo quanto às modificações do estatuto. No entanto, penso que o nosso ponto de vista é praticamente aceito. Aguardamos avisos a data da reunião para partirmos para S. Paulo. Creio que irão uns 10 ou 12 apenas.

Estou trabalhando firme pela Revista e nesse sentido peço-lhe urgentemente uma "nota" sobre o próximo concurso com os títulos das theses etc. etc. e um ou mais trabalhos com absoluta urgência.

Para evitar aborrecimentos e mal entendidos, resolvi arcar sozinho com a responsabilidade da Revista, evitando convidar ou criar Conselhos de redação, colaboradores etc. Só assim contentarei todos. Serei o diretor responsável e a Revista conta com a colaboração dos mais respeitados orthopedistas e traumatologistas do paiz e do extrangeiro. Conto principalmente com os amigos certos, como Você, Define, Orlando e os demais amigos do Pavilhão e com um bom grupo do Rio e do extrangeiro. Se tudo correr como quero no próximo mês ella sahirá e vencerá.

Escreva-me logo sobre o assumpto e aceite com um abraço à D. Odilla a amizade sincera de

Achilles (de Araújo)

P.S. O Zezito de viva voz porá V. ao par de certas cousas. 


\title{
REVISTA BRASILEIRA
}

\author{
DE \\ ORTHOPEDIA E TRAUMATOLOGIA
}

DIRECTOR - FUNDADOR

ACHILLES DE ARAUJO

$\longrightarrow$

INDICE GERAL

DO VOLUME I

$(1939$ - 1940)

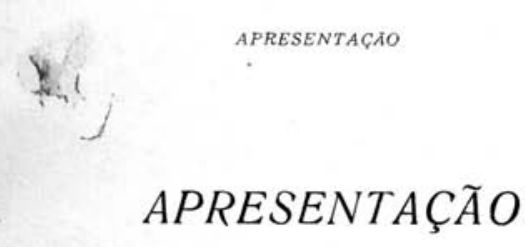

1.

Publicação bimestral

RIO DE JAN

Com o presente fasciculo, inicia a "Revista Brasileira de Orthopedia e Traumatologia" a tarefa a que se propoz - ser o repositorio e ao mesmo tempo a divulgadora da producção scientifica dos que entre nós se dedicam ao estudo desses assumptos e uma collahoradora dedicada e enthusiasta da obra que vem brilhantemente realizando a Sociedade Brasileira de Orthopedia e Traumatologia em pról do conceito de autonomia dessas especialidades que se completam.

$O$ numero sempre crescente de trabalhos scientificos sobre a pathologia e a clinica dos orgãos do apparelho locomotor, dispersos em numerosos periodicos de medicina do paiz e mesmo do extrangeiro, mostra exuberantemente o interesse que vem dispertando, em. nosso meio, a especialidade, e a necessidude, para melhor aproveitamento do esforço dos que a ella se dedicam, de unil-os numa revista que tenha por escopo unico occupar-se desses assumptos.

A "Revista Brasileira de Orthopedia e Traumatologia" apparece como uma consequencia logica dessas affirmativas e está certa que, reunindo e divulgando a producção technico-scientifica dos cultores da especialidade no Brasil, e tornando-se, como deseja, campo efficiente de estudo dos multiplos e complexos problemas medico-sociaes que a Orthopedia e a Traumatologia ainda apresentam, está certa, repetimos, que fará obra util e patriotica.

ACHILLES DE ARAUJO 